\title{
Integrating Historical and Societal Contexts in the Computing Curricula
}

\author{
John IMPAGLIAZZO \\ Department of Computer Science, Hofstra University; John.Impagliazzo@Hofstra.edu \\ John A.N. LEE \\ Virginia Tech and Radford University; janlee17@verizon.net \\ David C. CASSIDY, \\ Division of Natural Science, Hofstra University; chmdcc@optonline.net
}

\begin{abstract}
This paper provides instructors of computing a method to integrate computing history in the computing curriculum and to elevate the awareness of the social context of the subject. It provides suggestions by which instructors can enrich the curriculum by including history in the subjects they teach, even though they may not have had formal education in computing history or the history of science. Using history in computing very often stimulates discussion and dialogue among students and makes them aware of the social consequences of the computer systems they will use, help design, or create. Instructors can enrich the courses they now teach by integrating social and historical interludes within them.
\end{abstract}

Key words: Computing history, societal issues, computing curricula, computing in society

\section{INTRODUCTION}

The computing community has witnessed a resurgent interest in computing history. This is only natural, as time diminishes the ability of early pioneers to record the achievements and contributions they have made to the computing field. In an effort to preserve historical achievements, different institutions around the world (see Appendix A) and many history zealots have championed and preserved a new interest in computing history. Recognized historians have also promoted this interest through their publications and historical websites. 
Despite this recent fervor in computing history, little has filtered into the educational arena. While pocket interests appear in specialized courses in schools, colleges, and universities, little historical content has reached the mainstream areas of education. Very few computing programs formally integrate computing history within their curricula and even fewer offer courses related to the history of computing. In contrast, one can easily demonstrate mathematical curricula that have courses or course content in the history of mathematics. Since the 1960 s, organizations such as the ACM [ACM68, ACM78, Tucker91, ACM93], the IEEE Computer Society [IEEECS83], the Association of Information Technology Professionals [Longenecker97], and committees of UNESCO [Mulder00] have produced curriculum recommendations in computing. Only recently, in Computing Curricula 2001 [IEEECS01], has the history of computing received acknowledgment and credence by including it as knowledge components within the curriculum recommendation.

Furthermore, the history of computing has affected the information society in which we live. Many documented cases such as the Therac instance [Leveson93] exist where historical reflection would have saved human lives or economic loss. In this case, several people had died because of the faulty functioning of software that operated an x-ray machine. Have we as computing professionals learned lessons from such past failures? Have we learned lessons from past successes? When the educational computing culture does not encourage history to be part of a computing curriculum, we cannot expect the professionals of tomorrow-whether in the academic, industrial, or governmental spheres-to make informed decisions when they have not experienced the lessons from the past. This is another reason why computing history is important for all computing professionals and why it should be part of the computing curriculum.

In summary, we can learn much from history. From a cultural standpoint, history broadens one's perspective on the field. It allows students and scholars to explore the thinking and decisions of people as well as the socio-technical dynamics in the development, use, and reappropriation of technological resources. From a practical standpoint, history enables individuals and enterprises to learn from the events of the past and to improve on those experiences. Both views are necessary to create an informed computing professional. Computing history should be a part of human understanding. It should also demonstrate how the development of computing has affected people and their social environment. In more advanced settings, students should be able to do a critical analysis of significant moments in the history of computing, including the social, biographical, and economic contexts of development. In this spirit, this work provides a rationale by which educators at all levels can use history to 
enhance and enrich their current courses by integrating computing history within them.

\section{SUMMARY OF THE IFIP REPORT}

In 1998, the International Federation for Information Processing (IFIP) adopted the report entitled "History in the Computing Curriculum," referred herein as the "IFIP Report." An IFIP joint task group (TC3 and WG 9.7) developed the IFIP Report and the technical committees TC3 and TC9 endorsed it in the summer of 1998. The journal IEEE Annals of the History of Computing published the report in 1999 January [Impagliazzo99]. A prepublication electronic version of the report is also available [http://www.CompHist.org]. The IFIP Report has created much interest as educators have used it as a basis for presentations at different conferences. Appendices $\mathrm{B}$ and $\mathrm{C}$ illustrate some resources that are similar to those appearing in the IFIP Report. Appendix B provides some literary works; Appendix $\mathrm{C}$ illustrates some useful websites. We include them here as a convenience to the reader.

The IFIP Report provided a framework for a curriculum by proposing a knowledge base of suggested topics. It also included resources applicable to undergraduate degree programs offered at institutions of higher learning. It was international in scope and was applicable to all computing disciplines. It sought to raise the awareness of history and showed how people could use the report to improve their study and practice of the computing profession. The increased awareness of computing history has highlighted the importance of history as a tool for learning for students and practitioners, and underscored the rationale that history should be part of the computing curriculum at all levels of study.

The objectives of the IFIP Report suggested that computing history should be a part of the formal education of students, particularly those studying computing. The report fostered that concept of learning through one or a combination of the following forms:

- An integrated approach where history becomes a part of existing courses,

- A single course for computing specialists who have completed at least one year of study in their specialty,

- A single course with no prerequisite open to all students.

The report also provided hints on how educators in the computing field could make history exciting within the context of the computing curriculum. It did this by providing suggestions for course outlines, texts, resources from different media, and sample curricula so educators could have access to 
tools and resources needed to implement a successful inclusion of the study of computing history in the computing curriculum.

\section{OVERVIEW OF THIS PAPER}

This chapter is an extension of the IFIP report. It shows how the establishment of a history component in the computing curriculum can have a two-fold effect on students by (1) enriching their course of study through an appreciation of the origins of accepted concepts and techniques, and (2) demonstrating how events from the past affect contemporary computer science and ultimately the society in which we live. It focuses on the integration of societal and historical contexts throughout the computing curriculum not only to highlight how people have shaped the field, but also to emphasize the importance of the broader consequences and contexts of historical events. Through examples, it will show how historical events affected the socio-technical dimensions of a global society. This paper will also suggest ways in which society can benefit from the lessons of the past so that computing professionals can make decisions not only from economic considerations, but also from societal and cultural perspectives.

The approach taken here is to suggest how instructors can establish their own knowledge base of possible topics from computing history and incorporate these topics within the curriculum. The manner and depth of inclusion of these topics will vary according to the needs of the presenters and the context in which they present the material. Teachers of computing can incorporate the topics from the knowledge base into their existing courses. In courses for non-computing specialists, teachers would temper the inclusion of their knowledge base according to the level of the student and the intent of the course.

\section{SOCIETAL PERSPECTIVES ON COMPUTING HISTORY AND CURRICULA}

For the student of computing, there is a need to understand how this field has developed and matured. How many computing students know of the challenges that faced early computing pioneers and how they overcame those challenges at that time? How many students understand the social and ethical implications of the design of computer systems? Students should be aware of the principal people and the broader contexts and events that have shaped their profession. They should also understand how computational ideas and products have influenced our society. Students can learn from experiences: the successes and the failures. In doing so, students will 
become better global citizens and professionals. The history of computing can make that happen.

Computing professionals of all types can benefit from history. In academia, computing history can add new dimensions to courses by allowing students to reflect on past events and to conceptualize a background of their studies. In industry and government, past mistakes, misconceptions, and successes can form a basis for developing new ideas and implementing and promoting new frontiers in computing. For global citizens, computing history adds perspective to the establishment of their pursuits in a technological society.

As mentioned, the growing interest in computing history and student learning has yet to receive priority for curriculum inclusion. Part of the reluctance is the ongoing augmentation of technical topics in an already seemingly crowded curriculum. A special course on the history of computing would be ideal, but would most likely compete with a course of technical interest. To complicate the issue, teachers of computing courses have little formal study in computing history and, consequently, are hesitant to discuss computing history within their technical courses or as a special course on the subject. Although computer history institutes and museums have been diligently collecting artefacts, interviews, and archival sources (e.g. see Appendix A), these materials are not yet fully catalogued or easily accessible-either on-line or in hard copy-for use by teachers and students.

\section{KNOWLEDGE CLUSTERS FROM HISTORICAL PERSPECTIVES}

In an effort to assist instructors integrating historical and societal contexts in their computer curricula, the IFIP report provided some examples of how they can develop a topic by developing "clusters" of information to help form a knowledge base. To encapsulate structure, we had partitioned a cluster into four sections identified as Subject, Description, Topics, and Activities.

Instructors should start by developing these and/or their own clusters on topics of their choosing and caching them for eventual use in the curriculum. Several clusters per course would be a good starting point. at the appropriate time, instructors can introduce a cluster in a course. This would provide a handy set of topics and assignments to help them in the instruction process. Pre-developed clusters will help ensure that some appropriate historical/social topics will complement technical content and that assignments are available, if needed. Clusters also help avoid the "ad hoc" manner of introducing material on history, especially if students are aware that they will receive a grade on the material. 
Our own experience has shown that the use of several cluster-topics per semester gives the students a welcome change of pace in the content of the course and provides a contextual perspective on the technical material of the course, enabling a deeper sense of the meaning and significance of the technical aspects. In Appendix D, we present some representative examples of historically oriented social clusters that follow this model. We encourage instructors to experiment with clusters either through their own design or by modifying those presented to reflect their own styles and needs.

\section{COMPUTING ISSUES AFFECTING SOCIETY}

Computing issues affecting society involve broader societal issues that have affected the development of the computer itself. The immediate commercial, scientific, and military applications have driven the initial development of the computer and its uses, and they are still significant today. The nearly unlimited flexibility of computer applications has enabled such applications to extend far beyond their initial purposes, touching upon nearly every facet of contemporary life, as well as upon many other unrelated technologies. Because of this, the computer's effect upon society is becoming equally diverse and nearly universal. While these effects involve new social consequences or hardly recognized social issues unique to the technology itself, in most cases the effects have magnified or resolved previously existing problems. They have also added new dimensions to already existing situations. Such issues as privacy, freedom of information, economic stratification, work environments, and copyright protection were hotly debated long before the advent of computers. Other social issues, such as access of physically challenged people to computers, computer access by economically or educationally disadvantaged, uses of computers in education, and "cyber crime" embody qualities unique to computer technology.

Because of the tremendous impact of computers upon society, it is important that future computer professionals are aware of the past, present, and possible future influence of their work and its consequences, both in positive and in negative terms. Through the inclusion of historical examples bearing on contemporary and emerging issues, we can effectively accomplish building such awareness into the computer science curriculum. 


\section{KNOWLEDGE CLUSTERS FROM SOCIETAL PERSPECTIVES}

Following the model presented in the IFIP Report, Appendix D shows eight representative examples of schematic knowledge clusters on a wide range of computer-related social issues. Where appropriate, each knowledge cluster encourages students to examine the broader issues involved, both past and present, the impact of the introduction of computer technology, and the viability of possible ways to resolve or improve the situation in the future.

The clusters of Appendix D differ from those appearing in the IFIP Report. In addition to Subject, Description, Topics, and Activities, the societal clusters include an additional section called Discussion. Under Discussion, we pose some questions to stimulate class participation and interaction. Clearly, these questions act as guidelines with the hope of stimulating further questions either from the students or from the instructor. Ideally, discussion should occur after students have performed the activities related to the topics of the subject. Appendix E contains suggested resources that may be useful in developing new clusters for some courses.

\section{ESTABLISHING AN HISTORICAL CONTEXT OF KNOWLEDGE}

It is difficult to state which topics or events from history should appear in the background of a student. Many events mark different milestones in the historical evolution of computing. Identifying them is not easy. This becomes especially true when viewed in the context of courses for specialists (majors) versus courses for non-specialists (non-majors). The IFIP Report suggested a possible knowledge base. In reality, there are many possibilities. What is important is to identify courses and to include within them historical interludes to spark greater (human) interest in the technical topic and to show the broader effects of the topic.

One way to spark interest is to have students review historical chronologies and search out broader events over time that have influenced the course of a particular topic. The online version of the IFIP Report shows one such chronology; there are many others (see Appendix F). For example, we have found that exploring the historical forces and the people behind the invention of the transistor and its uses, or the story of Bill Gates and the rise and continuing saga of Microsoft, or the history of operating systems have caused a burst of student excitement and class discussions. Human, social, and economic factors start playing a role. Some students may be reticent to discuss openly a technical aspect of operating systems. However, the historical evolution of operating systems, for example, suddenly motivates 
them by an understanding and appreciation of early challenges and struggles leading to a better understanding and appreciation of the status of the subject. In addition, lively discussions have occurred on how operating systems affect society and why some systems have succeeded while others have failed. Overall, computing instructors should formulate their own contexts of knowledge and apply them in their own manner within their courses.

As a curriculum example, suppose one were teaching an overview of computing course for non-specialists. The context of knowledge in this case might consist of a collection of events that highlight the evolution of computing. These might include some of the so-called "firsts" that have achieved recognition by historians such as the first computer, the first programming language, the first operating system, the first mouse, and the first microprocessor. The teacher can easily change the thread of conversation to discuss the broader factors motivating the development of these "firsts," followed by their effect on different societies as they were introduced and how they eventually changed the culture in which people live.

As another curriculum example, suppose someone were teaching a computing course in programming. Irrespective of the language used, it is possible to provide interludes of history as the course progresses. The context of knowledge in this case might include events such as the evolution of an early programming language (say FORTRAN or ALGOL), the development of language paradigms, and the historical development of the language under discussion. The teacher can discuss how programming languages differ from natural languages and how programming affected different global societies in which it was applied.

In each of these two examples, we would encourage instructors to develop a "knowledge cluster" that focuses on a particular aspect of the subject. In this manner, instructors will be prepared (similar to having a lesson plan) to include the historical topic within their technical courses.

\section{MAKING IT HAPPEN}

The key to success is to seize historical opportunities within courses that can generate further interest in the topics of computing. Sometimes instructors plan these opportunities; sometimes they occur spontaneously. Ideally, all instructors of computing should possess a sufficient and scholarly background in computing history. In reality, only very few can legitimately claim to be computing historians. The lack of formal preparation in computing history, however, should not deter instructors from including history in their courses. 
One approach is to develop knowledge clusters on particular areas of interest as mentioned in the previous section. Using the aforementioned models as a guide, instructors will find it easy to include the historical or social experience within areas of their technical interest. At the appropriate moment, instructors will be ready to include meaningful historical content in their courses.

Another approach is to have instructors enrich their own area of technical interest with computing history. They can do that in their own manner and in many different ways. One way is a time-categorical overview of the subject of interest by partitioning the evolution of the subject into categories over time. An obvious partitioning is as follows: early stages, developing era, modern events. By collecting historical information on their subject and organizing them in these categories, instructors would be ready to insert historical interludes within technical presentations in their courses. Still another approach is to focus on the development of several important areas of a topic of interest. The subject of hardware, for example, contains many topics. One hardware topic is peripheral devices. Instructors may consider the development of this topic from a time perspective by tracing the development of, say disk drives, over time. They may even consider an industrial perspective on the subject by discussing corporate approaches to the manufacture of such devices. A business-oriented computing course may take advantage of this approach.

In special cases, it is possible to assign projects on the history of computing and to study the impact of computing on society. Instructors can accomplish these projects at all levels of study. The purpose of a project is to allow students to apply the methods of scholarship to the study of computing history. In this setting, students can undertake a significant selfdirected historical inquiry. They can use historical sources effectively by locating and using primary, secondary, and tertiary sources, periodical literature, and electronic information. We caution that projects are not for everyone and instructors should use this approach judiciously.

Instructors can employ other interesting and exciting paradigms to make history happen in a curriculum. Indeed, we encourage faculty members to explore different ways to present computing history in their courses and to use the method that best suits their philosophy, their students, their institution, and their topic of discourse.

The crucial factors in making history happen in a course or curriculum are attitude and desire. Instructors need to focus not only on technical elements of the subject, but also on the historical flavors surrounding them. Weaving historical interludes within technical content makes courses exciting and real. Instructors can use this method to show how the dynamics of a topic or subject developed and continues to develop. Additionally, students enjoy the experience and often look forward to the social realities 
and the human side of the material they study. It also reinforces their interest in the subject and makes them better students.

\section{ASSESSING PROGRESS}

As with all educational experiences, some form of assessment is necessary to measure and evaluate performance. Using historical interludes in technical courses without a measure of student accountability causes an unspoken void and leaves students with the impression that the material is not important. It is essential that instructors assess the progress made by their students in all areas of their studies, including the interludes. If instructors assess students by examination, then they should include at least one question on the socio-historical content.

We would expect students emerging from an experience on the history of computing to be conversant on various topics of the field. They should be able to relate concepts and topics with people, time, and places and be able to have informed opinions on the social consequences of using computer in society. When that occurs, instructors will have achieved the goal of having students consider the social context of their technical abilities.

\section{CONCLUSIONS}

The intent of this paper is to provide instructors of computing with suggestions on how to integrate history in computing and how to make students more aware of the social context of the subject. The work has provided suggestions by which instructors who have not had formal education in computing history or the history of science and technology can still enrich their curriculum by including history in the subjects they teach. We hope that the use of history in computing will stimulate discussion and dialogue among students and render them more aware of the social consequences of the computer systems they will help design or create. In this spirit, our hope is that instructors will enrich the courses they now teach by integrating social and historical interludes within them. We believe that students and society will benefit from this experience.

\section{ACKNOWLEDGEMENTS}

The authors wish to acknowledge the members of the TC9 Committee for their review and input. They would also like to thank their students who 
have commented and benefited from using historical and societal issues in their studies.

\section{REFERENCES}

[ACM68] ACM Curriculum Committee on Computer Science. Curriculum '68 Recommendations for Academic Programs in Computer Science. Communications of the ACM II (3) (Mar. 1968): 151-197.

[ACM78] ACM Curriculum Committee on Computer Science. Curriculum '78 Recommendations for the Undergraduate Program in Computer Science. Communications of ACM 22 (3) (March 1979): 147-166.

[ACM93] ACM Two-Year College Computing Curricula Task Force. Computing Curricula Guidelines for Associate-Degree Programs. 4 vols. New York: ACM Press, 1993.

[IEEECS83] IEEE Computer Society Educational Activities Board / Model Program Committee. The 1983 IEEE Computer Society Model Program in Computer Science and Engineering. New York: IEEE Computer Society, 1983.

[IEEECS01] IEEE Computer Society and ACM, Computing Curricula 2001 - Computer Science, <http://computer.org/ education/cc2001/final/index.htm>, 2001

[Impagliazzo99] Impagliazzo, John, et al. History in the Computing Curriculum, IFIP (TC3WG9.7 Task Group) Report. Task Group Chair. IEEE Annals of the History of Computing, January 1999.

[Leveson93] Leveson, Nancy and Clark S. Turner, An Investigation of the Therac-25 Accidents, IEEE Computer, Vol. 26, No. 7, July 1993, pp. 18-41.

[Longenecker97] Longenecker, Herbert E. Jr, David L. Feinstein, John T. Gorgone, Gordon B. Davis, J. Daniel Couger, co-chairs. IS'97. Model Curriculum and Guidelines for Undergraduate Degree Programs in Information Systems. ACM Press, 1997.

[Mulder00] Mulder, Fred, and Tom van Weert, IFIP/UNESCO's Informatics Curriculum Framework 2000 for Higher Education, Proceedings of the IFIP World Computer Congress 2000, International Federation for Information Processing, 2000.

[Tucker91] Tucker, Allen B., et al. Computing Curricula 1991 - Report of the ACM/IEEEComputer Society Joint Curriculum Task Force. New York: ACM Press, 1991. Reprinted in summary in Communications of the ACM 34 (6) (June 1991): 68-84. 


\title{
APPENDIX
}

\section{Appendix A}

\author{
Some Institutions Dedicated to Computing History \\ 1. Charles Babbage Institute (Minnesota) \\ 2. Computer History Museum (California) \\ 3. Deutsches Museum (Munich) \\ 4. Heinz Nixdorf Museum (Paderborn) \\ 5. IEEE History Center (New Jersey) \\ 6. Museum of the History of Science (Oxford) \\ 7. Smithsonian Institution (Washington, D.C.)
}

\section{Appendix B}

\section{Some Journals, Textbooks, General Works, and Monographs on Computing History}

\section{Journals}

IEEE Annals of the History of Computing; IEEE Computer Society, Los Alamitos, California.

Technology and Culture; Society for the History of Technology, Dearborn, Michigan.

Textbooks and General Works

Aspray, William (Ed.); Computing Before Computers, Iowa State University Press, 1990.

Augarten, Stan; Bit by Bit: An Illustrated History of Computers, Ticknor \& Fields, 1984.

Campbell-Kelly, Martin and Aspray, William; Computer: A History of the Information Machine, Basic Books, 1996.

Lee, John A.N.; Computer Pioneers, IEEE Computer Society Press, 1995.

Randell, Brian (Ed.); The Origins of Digital Computers, Springer-Verlag, 1982.

Williams, Michael R.; A History of Computing Technology, Second Edition, IEEE Computer Society Press, 1997.

\section{Specialist Monographs}

Austrian, Geoffrey D.; Herman Hollerith: Forgotten Giant of Information Processing, Columbia University Press, 1982.

Bergin, T.J. and Gibson, R.G.; History of Programming Languages, ACM Press, New York, 1996.

Hodges, A.; Alan Turing: The Enigma, Simon and Schuster, New York 1983.

Pugh, Emerson W.; Building IBM: Shaping an Industry and its Technology, MIT Press, 1995.

Wexelblatt, R. (ed.); History of Programming Languages, Academic Press, 1981.

\section{Appendix C}

\section{Websites Useful for Computing History}

Some web sites useful in the computing curriculum

American Computer Museum in Bozeman, Montana: http://www.compustory.com

Charles Babbage Institute, Center for the History of Computing. University of Minnesota: http://www.cbi.umn.edu

Computer Conservation Society. British Computer Society and the Science Museum of London: http://www.cs.man.ac.uk/CCS

IEEE Annals of the History of Computing: http:/www.computer.org/pubs/annals/annals.htm

Hobbes' Internet Timeline: http://info. isoc.org/guest/zakon/Internet/History/HIT.html

Impagliazzo History Site: http://www.CompHist.org

Lee history site: http://ei.cs.vt.edu/ history/index.html 
Virtual Museum of Computing, Oxford University: http://www.comlab.ox.ac.uk/archive/other/ museums/computing.html

\section{Appendix D}

\section{Examples of Clusters Emphasizing Social Issues}

Computing issues affecting society entwine themselves with many of the other broader issues facing society and with the development of the computer itself. The issues and their resolution can change with society's changing social, economic, and governmental priorities, as well as with advances in computer technology. Each cluster contains the historical background as well as the contemporary status and potential future development of the issue.

\section{Cluster 1}

Subject:

Government-related Issues

Description:

In the United States, federal funding helped foster computer technology and protect American interests. Examine the government's past role in the growth of this technology, and some of the issues relating to the impact of computing technology upon government functions.

\section{Topics:}

National issues: Government role in fostering computer technology-past and present.

Privacy issues: Previous and present privacy legislation, freedom of information

Defense issues: Role of the military in computer development, the "computer battlefield," origins of the Internet, and combating terrorism.

Political issues: Uses of computers in prior presidential election campaigns, citizen lobbying, freedom of speech

\section{Activities:}

Use the Internet to research early and more recent government defense and science initiatives relating to computer technology development of one or more countries. Find an abbreviated government budget report and the amounts allocated to various agencies for computer science and technology. Examine one or more of the resulting government uses of the new technology.

\section{Discussion:}

What has been the role of the national government in the development of computer science and technology? Why was the national government involved? Would computer technology be the same today without governmental support in the past and present? How has the new technology transformed government functions?

\section{Cluster 2}

Subject:

Free Market Issues

\section{Description:}

Consider several important anti-trust and copyright or patent infringement cases past and present, and how their outcomes have affected or will affect the computing industry.

Topics:

The Atari vs. Nintendo case

The Apple vs. Microsoft case 
The United States government (and nine states) and the European Union vs. Microsoft

\section{Activities:}

Research each of these cases, the issues involved on both sides, the outcome in each case, and the impact or potential impact on the perceived problem.

\section{Discussion:}

Since governments have played a key role in promoting computer technology and its economic development, what role should it have, if any, in the computer marketplace. What has been the general complaint about Microsoft in the Microsoft-related cases? Do you think this is fair? What should be the role of businesses and corporations.

\section{Cluster 3}

\section{Subject:}

Computers in Education

\section{Description:}

Consider how educational institutions have utilized computers in the past and how they might better use them in the future.

\section{Topics:}

Computer assisted learning-pros and cons

Status of computers in elementary education,

Status of computers in higher education (e.g. science education)

Changing computer literacy

Filtering Internet and web content in schools and libraries

\section{Activities:}

Research how educational institutions have used, or not used, computers. Determine the impact of computing technology on students' learning. Examine the pros and cons of content filtering in schools and libraries.

\section{Discussion:}

People have said that more computers in the classroom and access to the Internet will enhance education. So far, have computers and the Internet really enhance education? What place have computers had in education, and should this change? What are the issues involved in filtering efforts?

\section{Cluster 4}

\section{Subject:}

Computers and Work

\section{Description:}

The office computer arose from a confluence of electronic technology and office machinery. Consider how the computer was introduced into the work place (office and non-office), how it has affected the work environment, worker productivity, and the issues that have arisen as a result.

\section{Topics:}

Changing nature of work

Changing employer-employee relationship (monitoring etc)

Health related issues

Impact on employment and unemployment

\section{Activities:}

Research how the introduction of computers has affected each of the above topics.

\section{Discussion:}


What place has the computer gained in the work place? How did employees receive it initially? Was computer technology largely responsible for the economic boom of the $1990 \mathrm{~s}$, as some claim? What issues have arisen for employees, employers, and the economy in general as a result?

\section{Cluster 5}

\section{Subject:}

Selected Legal Issues

\section{Description:}

Consider the impact of computer technology on crime, law enforcement, and such legal issues as protection of intellectual property

\section{Topics:}

Crime: transforming cases in hacking, viruses, forgery, theft

Law enforcement: defensive measures, response to terrorism, Federal computer crime units.

Intellectual property: copyright laws, the United States vs. Napster case, piracy vs. innovation and free speech

\section{Activities:}

Examine some of the transforming cases in computer crime and the law enforcement response to them. Examine some of the legal, economic, and ethical issues involved in the Napster case.

\section{Discussion:}

How has computer crime changed over the years, and the response to it? What are your views on the issues surrounding the Napster case and similar services?

\section{Cluster 6}

\section{Subject:}

Science and Medicine

Description:

Scientific research has been a driving force behind computer development in past and it still is. The new technology has also benefited basic research in other sciences and the development of new tools and technologies in fields such as medicine. Consider the relationship between basic research and computers and the impact on medical diagnostic devices.

\section{Topics:}

Early research computers and their uses

Impact of computers on computer science

Current large-scale modelling (e.g. climate)

Applications of computer technology in medical imaging equipment (MRI, PET, CT)

\section{Activities:}

Examine the interaction between basic research and computer development, past and present. Give an example of how basic research enhanced computer technology, and vice versa. Research the origin and workings of one or more of the new medical imaging devices.

\section{Discussion:}

What has been the relationship between science and technology? How has computer science benefited from the growth of computer technology? What is the role of computers in medical science?

\section{Cluster 7}

Subject: 


\section{Perspectives and Policies on ICT in Society}

\section{Sociological Issues}

\section{Description:}

Computers have also had a direct impact upon individuals, their relationships with others, and in the economic and social structure of society.

\section{Topics:}

Isolation and changing relationships

Women, minorities, and computers

Disabled persons and computers

Changing social attitudes toward computer technology

Impact of computers on economic and social stratification

Computers and the changing quality of life

\section{Activities:}

Find research reports and discussions on some of the various aspects of the sociological impact of computers listed above.

\section{Discussion:}

What has been the sociological impact of computers? Is this a necessary consequence of the introduction of computers? Alternatively, is the impact a consequence of the way society introduced computers? How might society used computers to have a positive benefit for its people?

\section{Cluster 8}

Subject:

Ethical Issues

Description:

Computers have profoundly affected our ability to access and utilize private information, to manipulate social, economic, and political affairs, and to create advantages and disadvantages for different individuals and groups of people. Examine some of the ethical and legal issues involved, and their influence in the past and present.

Topics:

Codes of ethics

Legal vs. ethical issues

Social impact of computer ethics and computer law

\section{Activities:}

Research the Code of Ethics of the ACM and the IEEE Computer Society. Find and analyze some previous case studies of important ethical and legal situations. Think of a situation, real or imagined, in which you are confronted with an issue in each of these areas, and analyze your response to the situation.

\section{Discussion:}

What are the legal, ethical, and moral obligations of a computer scientist in an environment driven by economic and technological advances? Are there similar obligations pertaining to a computer-related corporation?

\section{Appendix E}

\section{Some Resources Related to Societal Issues and Computing}

\section{Printed Materials}

Baird, Robert M., et al. (eds); Cyberethics: Social \& Moral Issues in the Computer Age, (2000) Bowyer, Kevin (Ed.); Ethics and Computing: Living Responsibly in a Computerized World, (2000) 
Forester, Tom, Perry Morrison; Computer Ethics: Cautionary Tales and Ethical Dilemmas in Computing, (1993)

Hart, John; Ethics and Technology: Innovation and Transformation in Community Contexts, (1997)

Johnson, Deborah G.; Computer Ethics, 3rd ed., (2001)

Johnson, Deborah G. and Helen Nissenbaum (Eds); Computers, Ethics and Social Values, (1995)

Kallman, Ernest and John Grillo; Ethical Decision Making and Information Technology: An Introduction With Cases (1995)

Kizza, Joseph Migga, et al; Ethical and Social Issues in the Information Age (Undergraduate Texts in Computer Science), (1997)

Ohler, Jason; Taming the Beast: Choice \& Control in the Electronic Jungle (1999)

Schellenberg, Kathryn (Editor); Computers in Society 00/0I (Computers in Society, 8th Ed)

Spinello, Richard A.; CyberEthics: Morality and Law in Cyberspace, (2000)

Spinello, Richard A.; Case Studies in Information and Computer Ethics, (1996)

\section{Websites}

Check <http://courses.cs.vt.edu/ cs3604/support/FrontEnd/> by John A.N. Lee)

\section{Some Organizations}

(From <http://courses.cs.vt.edu/ cs3604/support/FrontEnd/> by John A.N. Lee)

ACM Special Interest Group on Computers and Society (SIGCAS).

Centre for Computing and Social Responsibility (CCSR)

Computer Professionals for Social Responsibility (CPSR)

Cyberspace Policy Institute, George Washington University

Electronic Frontier Foundation

Ethics Center for Engineering and Science

IEEE Society on Social Implications of Technology.

Joint IEEE Computer Society and ACM Steering Committee for the Establishment of Software Engineering as a Profession

Joseph \& Edna Josephson Institute of Ethics

Markkula Center for Applied Ethics

National Institute for Engineering Ethics

Poynter Center at Indiana University-Bloomington

U.S. Office of Government Ethics

Web Clearinghouse for Engineering and Computing Ethics

\section{Appendix F}

\section{Chronologies of Historical Events in Computing}

Many chronologies of historical events exist. Some of these include:

Chronology of Personal Computers: http://www.islandnet.com/ kpolsson/comphist/

Chronology of Digital Computing Machines: http://wilson.best.vwh.net/faq/chrono.html

Hobbes' Internet Timeline: http://info.isoc.org/guest/zakon/Internet/History/HIT.html

IFIP WG 9.7: http://www.CompHist.org/

Yahoo! Computers and Internet History:

http://dir.yahoo.com/Computers_and_Internet/History/ 